\title{
EL JUEZ-LUCHADOR Y EL HISTORIADOR-POLÍTICO: IMAGEN Y RESPUESTA POLIBIANA A UN CONFLICTO HELÉNICO
}

\author{
Juan Pablo Prieto Iommi \\ Instituto de Historia - Pontificia Universidad Católica de Valparaíso. Chile
}

Resumen: deteniéndonos en una analogía polibiana entre el pugilato y las opiniones populares en Grecia sobre la contienda entre Macedonia y Roma durante la tercera guerra macedónica, se puede determinar la existencia de una representación social previa que identificaba la lucha atlética con el combate político. Esta, utilizada por Polibio, sufrió una serie de cambios que se adecuaron a su propósito de adiestrar, con su narrativa histórica, al líder político griego sobre cómo lidiar con las masas populares $y$, consecuentemente, reconocer a Roma como un legítimo contrincante por el dominio universal y no un bárbaro. Se trataría esta narración, por lo tanto, no de una curiosidad o una alegoría artificiosa, sino de una herramienta conscientemente construida por Polibio para enseñar a sus lectores sobre la correcta praxis política.

Palabras claves: pugilato, praxis, política, masas, Roma, Macedonia, imperialismo.

\section{THE WRESTLER JUDGE AND THE POLITICAL HISTORIAN: IMAGE AND POLYBIAN RESPONSE TO AN HELENIC CONFLICT}

Abstract: taking a good look to a polybian analogy between boxing and greek popular opinions, concerning the struggle among Macedon and Rome during the third Macedonian War, it can be determined the existence of a pre-existing social representation wich identified the athletic fighting with the political combat. This analogy, used by Polybius, was subject of several changes in his historical narrative with the finality of training the greek politician in how to deal with the mob and, consequently, aknowledge Rome as a legitimate contender for the world empire rather than a barbarian. This polybian fragment would be, therefore, not an alegory or a curiosity but a consciously builted tool made for teaching his readers about the proper political praxis.

Keywords: boxing, praxis, politics, mob, Rome, Macedonia, imperialism.

Recibido: 21.03. 2014 - Aceptado: 24.04 .2014

Correspondencia: Juan Pablo Prieto Iommi. jpabloprietoi@gmail.com Licenciado y ayudante del Instituto de Historia de la Pontificia Universidad Católica de Valparaíso. Asistente Fondecyt No 1120487: Diplomacia y autorrepresentación en la Roma republicana. Fono: 56-32-481684 / cel: 62044908 
ara Polibio, la paz de Naupacto del 217 a.C. se trató de un evento clave
para la historia de la expansión y conquista romana por el mediterráneo.
Como él mismo afirma, es desde aquél momento que los eventos de hombres y estados del mediterráneo occidental y oriental se encuentran y unen bajo un mismo grupo de intereses y fortuna ${ }^{1}$.

En esta ocasión, el embajador etolio Agelao menciona el peligro de que los bárbaros romanos irrumpiesen en Grecia y acabasen con los “juegos” (agonían) con los que los helenos se entretenían. Este juego de palabras entre política y deporte en Polibio no es una excepción y menos aún una casualidad.

Como probaremos en este artículo, Polibio introduce en su obra la representación social del juego deportivo - particularmente el boxeo o pugilatocon vistas a explicar a su público greco-macedónico el reconocimiento de Roma como legítimo antagonista en busca del imperio, antes que un simple bárbaro, y el rol que en toda "lucha" política tiene el aprendizaje desde la narración histórica.

Para lograr este objetivo, seguiremos tres pasos: primero, expondremos algunos antecedentes históricos que testimonian la existencia en Grecia de una representación social de la lucha político-deportiva, precisando los roles de luchador, público y juez; segundo, rastrearemos y analizaremos estas representaciones sociales en la obra de Polibio, observando las particularidades polibianas en su construcción; finalmente, en tercer lugar, buscaremos probar la consonancia entre estas representaciones sociales y los propósitos historiográficos de Polibio en un punto crucial: la validez de la narrativa del historiador para enseñar a su público la correcta praxis política frente al imperialismo romano.

Luchadores, jueces y públicos: representaciones sociales del agón deportivo y el agón político

Para la antigua Grecia no es sorpresa admitir que el rol del luchador atlético obtuvo un papel de gran importancia como catalizador de violencia infra e ${ }^{1}$ Polibio. Historias, Madrid, Gredos (trad. Manuel Balasch R.), 1982. p.140 (V, 105, 4-6.). 
interestatal, agente panhelénico, promotor político y canon $\operatorname{artístico~}^{2}$. En lo referido a la relación entre política y atletismo, podemos rastrear una serie de imágenes que nos permiten proponer la existencia de una representación social que emparentaba las virtudes del combate deportivo con las del combate político ${ }^{3}$.

Podemos encontrar ejemplos ya desde la poesía Homérica con los juegos fúnebres en honor a Patroclo, que permiten reunificar y pacificar lúdicamente al ejército aqueo tras el regreso al combate de Aquiles, o la lucha de boxeo entre Odiseo disfrazado y el mendigo Iro, proponiendo el autor una sutil relación entre ficción, realidad y simulación que anteceden y anuncian la lucha mortal del héroe para recuperar su hogar y el honor ofendidos. Sin embargo, los casos más relevadores se encuentran en fuentes posteriores ${ }^{4}$.

$\mathrm{Al}$ respecto, un caso significativo lo podemos encontrar en la comedia griega del siglo V a.C., donde en el 405 a.C. Aristófanes expone en su obra Las ranas un particular símil entre contienda política y contienda deportiva. Como explica el Corifeo de la obra:

"Es de justicia que el coro sagrado recomiende y enseñe lo mejor para la ciudad. Y lo primero que nos parece es que todos los ciudadanos deben ser iguales y que hay que acabar con los temores. Y si alguno erró, engañado por los manejos de Frínico, mi opinión es que es preciso que los que metieron la pata entonces puedan arrojar de sí la culpa y liberarse de su error de otrora" 5 .

El fragmento nos revela tres elementos claves. En primer lugar, nos habla de una crítica política, pues se trata de aquél Frínico promotor de la nefasta revuelta oligárquica en Atenas del 411 a.C. En segundo lugar, Aristófanes expone la presencia de un "coro sagrado" (jóron dikáion) que deberá indicar lo más justo para la ciudad, en este caso, perdonar a los que apoyaron al oligarca. Finalmente,

${ }^{2}$ Miller, S. G., Ancient Greek Athletics. New Heaven, Yale University Press, 2004, Pp. 216 - 234.

${ }^{3}$ Para más testimonios sobre la violencia física en las competencias atléticas griegas causada por conflictos políticos. Véase Garcia. R., F., "Violencia de los espectadores en el deporte griego antiguo". $C F C(G)$ : Estudios griegos e Indoeuropeos.2006,16.pp.139-156.

4 Homero, La Ilíada. Madrid, Gredos (trad. por E. Crespo), 2006, pp. 461 - 481 (XXIII, v. 255-897). Homero, La Odisea. Madrid, Gredos (trad. por J.P. PABÓN), 2006, pp. 293-295. (XVIII, v. 1-105).

${ }^{5}$ Aristófanes, Las ranas. Madrid, Gredos (trad. por Luis M. Macía Aparicio), 2007, p.265 (v. 686-691). 
y quizás lo más significativo, Aristófanes, al referirse a los "manejos" que ha hecho Frínico, utiliza la palabra sfálo, que quiere decir literalmente "hacer caer" o "hacer tropezar" al rival en la lucha deportiva ${ }^{6}$.

Si reunimos estas tres observaciones, podemos identificar la existencia de una configuración "deportiva" del acontecer político que el autor sabe bien que será reconocida por su audiencia. Existe el coro como juez del combate, a cargo de determinar vencedores y movidas ilegales; el luchador, como lo son Frínico y aquellos convencidos erróneamente por él, y un público de la obra teatral, a quien el coro indica el resultado de la contienda, la conducta "Ilegal" del político ateniense y el resultado deseado. Lo que trata de representar aquí Aristófanes, por lo tanto, es que Frínico, como un luchador que ha cometido una falta sometiendo de forma ilegal a su contrincante, ha engañado a algunos ciudadanos, y el coro, cual juez de una lucha atlética, debe corregir y rectificar pacíficamente el resultado por el bien de la polis o del público ciudadano asistente a la "lucha".

En un mismo sentido aporta Platón en su obra Las leyes, cuando explica la relevancia del Juez en la competencia deportiva a modo de imagen didáctica del estado gobernado justamente. Como dice el "Ateniense", protagonista del diálogo junto a Clinias, tras haber propuesto lo absurdo y problemático de una competencia sin categoría artística ni juez unívoco:

"Pues el juez está sentado no como alumno, sino más bien como maestro de los espectadores, como debe ser, para oponerse a los que dan a los espectadores un placer que no es ni conveniente ni correcto" ${ }^{\prime}$.

Otros ejemplos significativos los encontramos en los oradores del siglo IV a.C. En el caso de Isócrates, proponiendo un paralelismo entre combate oratorio y deportivo sobre la imprudencia de los jóvenes en política, afirma:

"Y lo que me parece más ridículo de todo es el intentar convencer con tales discursos de que poseen el arte de los asuntos políticos (...) hacen lo mismo que si uno fingiera ser el más fuerte de los atletas y descendiese a donde ningún otro estimaría digno. Porque ¿qué hombre bien intencionado intentaría alabar las desgracias?”8.

\footnotetext{
${ }^{6}$ Liddell, H.G. \& Scott, R., Greek-English Lexicon. Oxford, Clarendon. Press, 1961 .p. 1739.

7 Platón, Las leyes. Madrid, Gredos (trad. por Francisco Lisi), 2007, p. 257 (I, 658e).

${ }^{8}$ Isócrates, Discursos. Madrid, Gredos (trad. por Juan Manuel Guzmán Hermida), 2007.p.169.
} 
En un mismo sentido hablaba Demóstenes, defendiendo el buen actuar político a la luz de su contexto antes que por el afán de imitar proezas pasadas imposibles. Usando a los atletas Filamón y Glauco como ejemplos, indicaba que:

“...compara a quien está vivo con los vivos y con sus contemporáneos, como ocurre en todos los demás casos, los poetas, los coros, los luchadores. Filamón, no por ser más débil que Glauco el caristio y algunos otros atletas de anteriores tiempos, salía sin corona de Olimpia, sino que, porque luchaba mucho mejor que los que entraron a competir con él (...)También tú contémplate en confrontación con los oradores de ahora, contigo mismo, con el que quieras de entre todos: no esquivo a nadie" .

En todos estos casos, los oradores y estadistas juegan en sus discursos con las imágenes del luchador atlético y el competidor político, imágenes comprendidas por sus audiencias igualmente. Ambos testimonios apelan en última instancia a la mesura del contendor político, a medir sus fuerzas y a mantener un estatus en sus desafíos y debates con otros.

Son estos algunos ejemplos que revelan la amplitud de tiempo y públicos a los que la representación social del combate deportivo como contenedor a escala de los valores apropiados para el combate político alcanzó en el mundo griego hasta la época de Polibio $^{10}$. Examinemos ahora cómo estas representaciones encuentran eco en la obra del historiador.

\section{Representaciones sociales político-atléticas en las Historias de Polibio}

Las menciones en la obra de Polibio a cualquier competencia atlética presentan una constante a su base: todas ellas son utilizadas cuando una oposición políticomilitar ocupa su narración histórica. Sin embargo, algunas de estas menciones son más bien anecdóticas y no sobrepasan las simples similitudes de léxico. Otras, por el contrario, adquieren roles protagónicos en su narrativa. Examinemos tres casos ejemplares ${ }^{11}$.

${ }^{9}$ Demóstenes, Discursos: Sobre la Corona. Madrid, Gredos (trad. por A. López Eire), 2007, p. 517 (v. 318-320).

${ }^{10}$ Para otros muchos y detallados ejemplos, véase Miller, S.G. ARETE: Greek sports from ancient sources. Berkeley, University of california Press, 2004.

${ }^{11}$ A modo de ejemplo, véanse II. 65,11; III.81. 2-3; XXIX.8, 5; 8,9;17,4 y XXXVIII.18,8. Sobre el detalle filológico de estas menciones Foucault, J. A., Recherche sur la langue et le style de Polybe. Paris, Belles lettres, 1972, p.233. 
La primera mención interesante la encontramos en el libro primero de sus Historias, mientras narra la primera guerra púnica y la toma del mando púnico de Almícar Barca el 247 a.C. Aquí, queriendo Polibio enfatizar el sinnúmero de escaramuzas, movimientos militares y estratagemas que romanos y cartagineses ejercían uno sobre el otro, haciéndole imposible una narración detallada, afirmaba que:

"En efecto, como cuando, en la pelea por una corona, dos púgiles sobresalientes por su coraje y sus aptitudes se asestan ininterrumpidamente golpe tras golpe, a los espectadores y a los propios contendientes les es imposible realizar un pronóstico y explicar cada golpe y cada acoso" ${ }^{12}$.

El fragmento nos revela de forma evidente que Polibio conoce las representaciones sociales sobre política y atletismo y que, más aún, confía en su efectividad al punto que decide voluntariamente no narrar una serie de acciones militares extensas y engorrosas. Esto significa que su público, debiendo estar tan familiarizado con esta imagen, sería capaz de entender y justificar la decisión de Polibio, aún tratándose de no otra cosa sino el objeto mismo de su trabajo como lo es la expansión romana por el mediterráneo.

Quizás la mejor prueba de la propagación de esta representación la encontramos en el mismo Polibio dos libros más adelante en el año 218 a.C., durante la segunda guerra púnica, cuando Aníbal desea demostrar lo peligroso y comprometido de la situación en que se encuentran a su propio ejército una vez en Italia. Para ello, haciendo luchar prisioneros de guerra torturados por el premio de una muerte rápida, afirma el general púnico que: "había ordenado conducir allí a aquellos prisioneros para que el ejército viera en las desgracias ajenas su propia situación; así reflexionaría mejor sobre la situación presente"13.

Más allá de la realidad de esta historia- y a la cual Walbank tilda de "apócrifa"14 su utilización consolida la fuerza de la representación social de los combates para Polibio y su público. Se trata de construcciones simbólicas explicativas que autor, público y su contexto comparten.

\footnotetext{
${ }^{12}$ Polibio, Historias. p. 89 (I.57, 1-2).

${ }^{13}$ Ibíd., p. 292-293 (III.63, 2-3).

${ }^{14}$ Walbank, F. W., A Historycal Commentary on Polybius. Vol. 1. Oxford, Clarendon Press, 1957. p. 397.
} 
Sin embargo, estos fragmentos no resultan satisfactorios para entender cabalmente las representaciones sociales greco-macedónicas del imperialismo romano en este particular objeto de trabajo. Ello porque Polibio silencia la naturaleza de su audiencia en un caso y lo ignora por completo en el otro. Así, estas referencias adquieren un tono historiográfico, excusándose por una cuestión de método antes que reflejar una cuestión social particular. Es necesario observar otros casos.

Una segunda mención representativa la encontramos en su libro XVI, cuando Polibio detiene su narración al comienzo de la segunda guerra macedónica el 200 a.C. para reflexionar sobre la importancia del cálculo por sobre el entusiasmo en todo proyecto sometido a los vaivenes de la fortuna. Aquí, comparando al rey Átalo I con Filipo V, termina afirmando que:

"Me ha sugerido decir esto la realidad de que algunos, igual que hacen los corredores flojos en los estadios, abandonan sus propios proyectos cuando están a un paso de culminarlos, mientras que a otros precisamente esta circunstancia les lleva a superar al enemigo" ${ }^{15}$.

En este caso, Polibio revela la influencia platónica, pues el uso de este paralelismo se encuentra de forma casi idéntica en la República. Como afirma Platón en su obra:

“ $¡$ No son los hombres astutos e injustos como aquellos corredores que corren bien al partir pero no cuando se acercan a la meta? Saltan rápidamente al comienzo, pero terminan por hacer el ridículo, escapándose sin corona alguna..."16.

De este modo, Polibio vuelve a introducir una comparación atlética en un contexto político-militar, si bien en este caso su reflexión es no solo para justificarse metodológicamente, sino para confirmar un juicio historiográfico sobre el político y la forma de confrontar la adversidad de la fortuna propia o del contrincante.

Pese a lo anterior, seguimos teniendo un problema esencial: Polibio rehúye mencionar a un público concreto. A diferencia del caso de Agelao y los "bárbaros"

${ }^{15}$ Polibio, Historias. p. 43 (XVI.28, 8).

${ }^{16}$ Platón, Madrid, Gredos, (trad. por Conrado Eggers Lan), 1988.p. 478 (v. 613c). Confirma esta concordancia Walbank, F.W., A Historycal Commentary on Polybius. Vol. 2. p. 538. 
romanos, el historiador griego parece integrar con mayor profundidad en su finalidad historiográfica estas representaciones político-atléticas, dificultando precisar testimonialmente un individuo y una tradición específicos para dar con las representaciones sociales tras su trabajo. Sin embargo, un tercer y último caso nos podría permitir solucionar esta ausencia metodológica.

El fragmento se ubica en la descripción de los hechos del 171 a.C., correspondientes a la tercera guerra macedónica, tras la batalla de Calicino exitosa para el rey Perseo. Aquí, señalando el súbito y anteriormente escondido apoyo de las masas (ton polón) hacia el monarca macedonio, decide describir esta conducta de la siguiente forma:

“...lo ocurrido es semejante a lo que sucede en los pugilatos. En éstos, siempre que a un boxeador ilustre y que no ha probado la derrota, se le opone un rival desconocido y mucho más flojo, la plebe (ten pléthos) otorga al instante su benevolencia al inferior y le anima y se pone de su lado..." 17 .

Polibio no termina de utilizar esta comparación atlética aquí, agregando a continuación un ejemplo concreto. Menciona a los luchadores olímpicos de pugilato Clitómaco de Tebas y Aristónico, enviado este último por la monarquía Ptolemaica a la competencia. Siendo el tebano de reputación invencible, el público de la ocasión comienza por apoyar al retador egipcio. Sin embargo, cuando Aristónico se da cuenta de lo que ocurre, nuestro historiador indica que:

“...se volvió al público y le preguntó qué quería cuando aplaudía a Aristónico y era partidario suyo a más no poder. ¿Acaso no sabían que él mismo combatía hábil y correctamente? ¿O ignoraban que Clitómaco boxeaba por la gloria de Grecia, pero Aristónico por la del rey Ptolomeo? (...) Habiendo dicho esto Clitómaco, el cambio del público fue tal, cuentan, que Aristónico se vio derrotado más por los espectadores que por su mismo rival. Algo parecido fue lo que ocurrió a Perseo entre las turbas (toùs ójlous)"18.

Aquí encontramos entonces una mención de índole abstracta como las anteriormente mencionadas, pero ahora con un público específicamente griego al

${ }_{17}$ Polibio, Historias. p. 263 (XXVII.9, 1-2).

${ }^{18}$ Polibio, Historias. p. 264 (XXVII.9, 7-13). 
que Polibio menciona explícitamente para dar su punto a entender con claridad. El problema es, visto desde su punto de vista, que la opinión de la mayoría de los griegos frente a la guerra entre Roma y Macedonia es advenediza e irreflexiva. Sin embargo, la introducción de la pelea entre Clitómaco y Aristónico es donde se ponen en juego los principales componentes de la representación social, pues se trata de un ejemplo totalmente griego-helenístico para explicar un nuevo contexto greco-romano ${ }^{19}$.

La distancia que se percibe en cuanto representaciones sociales de aquellas expuestas en el discurso de Agelao el 217 a.C. son considerables. Ya Roma no es un "bárbaro" al que debe repelérsele ante el peligro de la esclavitud antinatural y despótica de los griegos. Ahora los romanos ocupan una posición de paridad competitiva, encarnando en Clitómaco un argumento griego sobre una decisión política de sumisión a una potencia capaz naturalmente de hacerlo como lo fue la Macedonia de Filipo V para Agelao. Ahora solo pervive una diferenciación cultural menor como lo indica el propio Clitómaco al dirigirse al público:

“¿Acaso pretendían que en la Olimpíadas se llevara la corona un egipcio tras derrotar a los griegos, y no que un tebano o un beocio fueran proclamados vencedores en el pugilato?"20.

Así, en definitiva, el problema ahora ya no es cómo evitar someterse a una dominación antinatural y barbárica, sino hacia cuál de estas dos opciones de dominación legítimas es mejor para Grecia tender: Roma o Macedonia.

Pero pese a lo anterior, resulta evidente que aquí no hay otros griegos salvo el historiador indicando la similitud con el caso romano. Queda en evidencia que Polibio, sin dudas, confía en una tradición previa de símiles político-deportivos para hacer entender su punto de vista frente al conflicto a sus lectores, pero ello no es lo mismo a decir que el uso que el historiador le da y las preconcepciones de su audiencia sean las mismas. Lo que aquí encontramos es un interés del autor

${ }^{19}$ A este respecto cabe destacar que el fragmento correlativo en Tito Livio sí recoge la primera parte prototípica sobre el pugilato, pero no la anécdota de Clitómaco y Aristónico. Livio, T., Historia de Roma desde su fundación. Madrid, Gredos (trad. José Antonio Villar Vidal), 1994, p. 147 (XLII, 63,1-2.).

${ }^{20}$ Polibio, Historias. p.265 (XXVII.9, 12). Sobre la sutil distinción entre griegos y el Egipto Ptolemaico en Polibio y bibliografía véase Walbank, F.W., "Egypt in Polybius". En Walbank, F.W. Polybius, Rome and the Hellenistic World. Cambridge, Cambridge University Press, 2002, pp.53-69. 
por hacer del "bárbaro" un rival legítimo (antagonistés) a los ojos de sus lectores, capaz de obtener la victoria y ser reconocida por todos como legítima y hasta necesaria. Como lo hacía Demóstenes e Isócrates en el pasado, Polibio recurre a la lucha atlética para comparar la lucha político-militar, pero va más allá y le otorga un uso inédito como analogía cultural.

Por lo tanto, la representación social aquí expuesta se encuentra mucho más comprometida con la historiografía polibiana, por lo que deberemos examinar cómo es que su interés por indicar a los romanos como contrincantes por sobre bárbaros se relaciona con sus objetivos como historiador.

\section{Público, luchadores y jueces: La expansión romana y la arena didáctica del historiador político}

Para desarrollar esta relación entre representaciones sociales y objetivos historiográficos, analizaremos la naturaleza de los tres elementos que confluyen en la lucha de boxeo narrada por Polibio para reflejar la situación griega del 171 a.C. y cómo estos son sometidos a una lectura polibiana específica y a sus objetivos metodológicos: la naturaleza voluble del público, la ausencia aparente de jueces y la conducta atípica de los luchadores.

En primer lugar, debemos destacar la descripción del público del pugilato como un símil con la de los pueblos griegos en el 171 a.C. Aquí, Polibio destaca el cambio súbito de actitud de la masa (poloi), la plebe (pléthon) o las turbas (ójlous) ante la inesperada victoria del más débil, indicando que si alguien las entiende a su debido tiempo, las masas muy pronto cambian de parecer.

Esta descripción no es casual. En términos generales, Polibio extrae sus conclusiones sobre la naturaleza de la masa popular desde su posición aristocrática y sus experiencias políticas leídas bajo esos cánones educativos. Se trata de una interpretación tradicional, donde "el pueblo" carecería de iniciativa, sería irracional e ingrato, codicioso $y$, a todas luces, inherentemente violento ${ }^{21}$. Es

${ }^{21}$ Sobre la influencia en Polibio de su educación aristocrática véase Mendels, D. "Polybius and the Socio-Economic Revolution in Greece (227-146 B.C.). AC51.1982. pp.86-110. EcKstein, A., Moral Vision in the Histories of Polybius. pp. $84-160$. Walbank, F. W. "Polybius' perception of the one and the many". En Walbank, F. W. Polybius, Rome and the Hellenistic World. p. 214. Para una reinterpretación actualizada del problema y enfocada en el desprecio polibiano hacia la democracia Champion., C., Cultural politics in Polybius' Histories. Berkeley, University of California Press, 2004. pp.188-189. 
así que el historiador homologa a las masas populares con los cambios del mar, cuando rescata las palabras de Escipión en el 206 a.C.:

"El mar y las multitudes padecen una enfermedad parecida: por su propia naturaleza el mar es inofensivo y seguro para los que lo utilizan, pero si el huracán se precipita violento encima de él, entonces demuestra a los navegantes cómo son los vientos que lo rodean; no de otro modo es la masa y se muestra a los que la sirven..."22.

Ahora bien, su descripción del "mar popular" introduce el problema del papel de los "líderes navegantes" en la política. Estos hombres de estado, pertenecientes a la élite social, deben prever los movimientos de esta fuerza humana y actuar en consonancia para evitar que desestabilicen el barco del estado. Es así que:

"El historiador consecuentemente da consejo a su audiencia aristocrática sobre cómo manejar el pléthos (...) consecuentemente elogia a aquellos hombre que intentan controlar a las feroces pasiones de la polloi, o de razonar con ellos sobre las consecuencias negativas a largo plazo de políticas tan solo momentáneamente atractivas"23.

Con esta actitud popular en mente, y el llamado de Polibio a una élite que la refrene mediante diálogo o la fuerza, el paralelismo de estas ideas historiográficas y la actitud del público en el combate de pugilato tratado aquí es significativo. Sin embargo, un problema surge: ¿dónde se encuentra en esta imagen del boxeo atlético el líder aristócrata que conduzca al pueblo tempestuoso? En este punto surge lo que creemos es una originalidad polibiana en el uso de la representación social del combate atlético-político, donde juez y luchador se entremezclan.

El luchador Clitómaco, aquél que interpela al público haciéndole ver su error en apoyar al rival, no era solo un gran atleta, como los numerosos logros y estatuas descritos por Pausanias lo indican, sino que, además, su templanza y prudencia eran conocidas por toda Grecia, al punto de ser famoso por rehuir los banquetes y todas sus tentaciones ${ }^{24}$. Su persona, entonces, inspiraba no solo

${ }^{22}$ Polibio, Historias. p.450 (XI.29.10-12). Otras menciones a esta idea de homologar al pueblo con el mar las encontramos en Homero, Iliada. II, v.144; Heródoto.VII, v.16a y Demóstenes. Sobre la Embajada, v.136.

${ }^{23}$ Champion., C., Cultural politics in Polybius' Histories. p. 138.

${ }^{24}$ Sobre las estatuas y triunfos de Clitómaco en Grecia véase Pausanias. Descripción de Grecia. Gredos (trad. por María Cruz Herrero I.). Madrid.1994, p 203 (VI.15, 3-5.). Sobre su templanza Plutarco. Moralia. Madrid, Gredos (trad. por Francisco Martín García), 1987, p.127 (VII.710E). 
respeto deportivo sino moral, haciendo de este un excelente ejemplo para Polibio y su preocupación por exponer la necesidad de mostrar a la masa estas actitudes de las que por naturaleza carecen.

Sin embargo, persiste el problema de la ausencia de una aristocracia estadista en el luchador, de ese carácter social diferenciado que le daría una naturaleza proclive al gobernar recta y justamente sobre el mar inconstante del pueblo. Es este punto nos ayuda a comprender esta decisión de Polibio el concepto de "Arena didáctica" que el historiador inglés James Davidson acunó en su artículo de 1991 titulado The Gaze in Polybius' Histories"25.

Desde el punto de vista de Davidson, la obra de Polibio reúne dentro de sí un conjunto de miradas y apariencias del mundo griego a las que el historiador, más que pretender homogeneizarlas bajo su propia convicción, desea exponerlas en sus diversas realidades y tensiones para que alcancen y sean significativas a la mayor cantidad posible de lectores; lo que él llama, en resumen, "a history about histories" 26 .

Ahora bien, en general no coincidimos en varios puntos con la apreciación de Davidson, pues, en su afán por estudiar en detalle la forma narrativa de Polibio, adjudica a este un estilo y composiciones que escapan a sus conocimientos y fines. En definitiva, una cosa es detectar en la escritura polibiana la existencia de recursos lingüísticos, narradores y audiencias silenciosas que no se corresponden con una escritura adecuada para nuestros rigores modernos, pero otra muy diferente es adjudicarle a torpezas y costumbres de redacción un sentido historiográfico superior.

Sin embargo, su estudio no deja por ello de ofrecer una disección minuciosa de la narrativa polibiana que puede aportar en revelar el sentido del luchadorestadista. Como dice Davidson, al concluir tras examinar varias metáforas atlético-políticas en Polibio:

"Estos pasajes deben ser puestos en contexto con un gran número de metáforas usadas por Polibio, que describen la guerra en términos de lucha-concurso (...) Si agregamos a los espectadores, podemos ir

${ }^{25}$ Davidson, J., "The gaze in Polybius' Histories". The Journal of Roman Studies.Vol.81.1991. pp.10-24.

${ }^{26}$ Ibíd., p.15. 
un poco más lejos que esto. Polibio presenta sus Historias, y quizás él mismo concibe a la historia así, como una arena didáctica. Los sucesos deben siempre soportar el peso de la observación" 27 .

Lo que nos indica aquí Davidson es importante, pues se condice con nuestra comprobación de la existencia de la praxis política como fin historiográfico que somete a las representaciones sociales en el caso de Agelao en Naupacto. Con Clitómaco y su audiencia, Polibio enfatiza la necesidad de la enseñanza mediante la observación de la acción política por sobre la teoría, ayudándose para ello de las representaciones sociales de la lucha atlético-política, si bien generando cambios en ella originales.

Polibio, entonces, en su interés por enfatizar la necesidad apremiante en Grecia de líderes prudentes, exitosos y capaces de dominar a las masas, y en oposición a la proliferación de demagogos, altera la representación atléticopolítica con sus elementos público-juez-luchador, uniendo en uno solo al juez y al luchador. Es así que se distancia de la representación dada por Platón, donde señala enfáticamente la necesidad del juez en todo certamen como la de un gobernante; para Polibio, la imagen didáctica debe ir más lejos y unificar ambos roles al punto de la indiferenciación. No debe el juez-gobernante solo administrar y dictaminar, sino que debe actuar, implicarse, entrar a la arena del combate y hacerse comprender expresamente por el pueblo-público. Se trataba de una convicción profunda que nacía de un temor igualmente profundo. Como indica Eckstein:

"La principal respuesta de Polibio a las amenazas al orden en su mundo es la de endurecer sus expectativas respecto a la única categoría de personas que cree capaces de administrar el estado: los hombres de la élite política (...) Debió haber sido el más profundo miedo de Polibio. Si el hombre maduro del estrato gobernante, frente a la avalancha de salvajismo e irracionalidad que amenazaba la sociedad, abandonaba sus responsabilidades por simple cobardía, debilidad moral o, peor, se unía a los salvajes, entonces nada estaba a salvo" 28 .

${ }^{27}$ Davidson, J., “The gaze in Polybius' Histories”. p. 15.

${ }^{28}$ Eckstein, A., Moral Vision in the Histories of Polybius. Berkeley and Los Angeles, University of California Press, 1995.p. 159. 
Es aquello lo que sus Historias pueden enseñarle y advertirle a su audiencia, y que el fragmento en cuestión lo pone en manifiesto. La historia es entonces para Polibio un espacio didáctico mediante ejemplos concretos de lucha política, donde el combate deportivo es una herramienta más en cuanto representación social significativa para sus lectores. El mensaje es, entonces, que Roma es ahora no un bárbaro, sino un legítimo antagonista en una legítima lucha al modo del pugilato, en donde el líder griego debe preocuparse por enseñar con el ejemplo de la acción concreta a las masas y fijar a su vez el camino a seguir que es, en este caso para Polibio, admitir la sumisión a Roma como una dominación natural y benéfica, no un gobierno despótico y barbárico. 


\section{Referencias bibliográficas}

Aristófanes, Las ranas. Madrid, Gredos (trad. por Luis M. Macía Aparicio), 2007.

Champion, C., Cultural politics in Polybius' Histories. Berkeley, University of Calfornia Press, 2004.

Davidson, J., “The gaze in Polybius' Histories”. The Journal of Roman Studies. Vol.81.1991. pp. 10-24.

Demóstenes, Discursos: Sobre la Corona. Madrid, Gredos (trad. por A. López Eire), 2007.

Eckstein, A., Moral Vision in the Histories of Polybius. Berkeley and Los Angeles, University of California Press, 1995.

Foucault, J. A., Recherche sur la langue et le style de Polybe. Paris, Belles lettres, 1972.

Garcia. R.. F., "Violencia de los espectadores en el deporte griego antiguo". $C F C(G)$ : Estudios griegos e Indoeuropeos. 2006, 16 pp. 139-156.

Homero, La Ilíada. Madrid, Gredos (trad. por E. Crespo), 2006.

Isócrates, Discursos. Madrid, Gredos (trad. por Juan Manuel Guzmán Hermida), 2007.

Liddell, H. G. \& Scott, R., Greek-English Lexicon. Oxford, Clarendon Press, 1961.

Livio, T., Historia de Roma desde su fundación. Madrid, Gredos (trad. José Antonio Villar Vidal), 1994.

Miller, S. G., ARETE: Greek sports from ancient sources. Berkeley, University of california Press, 2004.

Miller, S.G., Ancient Greek Athletics. New Heaven, Yale University Press, 2004.

Pausanias, Descripción de Grecia. Gredos (trad. por María Cruz Herrero I.). Madrid.1994.

Platon, La República. Madrid, Gredos, (trad. por Conrado Eggers Lan), 1988.

Platon, Las leyes. Madrid, Gredos (trad. por Francisco Lisi), 2007. 
Plutarco, Moralia. Madrid, Gredos (trad. por Francisco Martín García), 1987

Polibio, Historias. Madrid, Gredos (trad. Manuel Balasch R.), 1982.

Walbank, F. W., Polybius, Rome and the Hellenistic World. Cambridge, Cambridge University Press, 2002.

Walbank, F. W., A Historycal Commentary on Polybius. Vol. 1. Oxford, Clarendon Press, 1957.

Walbank, F. W., A Historycal Commentary on Polybius. Vol. 2. Oxford, Clarendon Press, 1984.

Walbank, F. W., Polybius, Rome and the Hellenistic World: Essays and Reflections. Cambridge, Cambridge University Press, 2002. 